\title{
Correction to: How common is germinal mosaicism that leads to premeiotic aneuploidy in the female?
}

\author{
Joy DA Delhanty ${ }^{1}$ (D) S Sioban B SenGupta ${ }^{1}$ (D) $\cdot$ Harita Ghevaria ${ }^{1}$ (I)
}

Published online: 9 December 2019

(C) Springer Science+Business Media, LLC, part of Springer Nature 2019

\section{Correction to: Journal of Assisted Reproduction and Genetics \\ https://doi.org/10.1007/s10815-019-01596-6}

The original article unfortunately contained a mistake. In the online version of the paper, the words "MII (metaphase II)PB1 (1st polar body) complex (MII-PB1 complex)" in table 1 are incorrectly placed.

The original version has been corrected.

The online version of the original article can be found at https://doi.org/ 10.1007/s10815-019-01596-6

Harita Ghevaria

h.ghevaria@ucl.ac.uk

Joy DA Delhanty

j.delhanty@ucl.ac.uk

Sioban B SenGupta

sioban.sengupta@ucl.ac.uk

1 Preimplantation Genetics Group, Institute for Women's Health, University College London, 86-96 Chenies Mews, London WC1E 6HX, U.K. 